\title{
Let's Be Friends: National Homophily in Multicultural Newcomer Student Networks
}

\author{
Kishore Gopalakrishna Pillai ${ }^{*}$, Constantinos N. Leonidou ${ }^{2}$, Xuemei Bian ${ }^{3}$ \\ ${ }^{1}$ Norwich Business School, University of East Anglia, Norwich, UK \\ ${ }^{2}$ Leeds University Business School, University of Leeds, Leeds, UK \\ ${ }^{3}$ Newcastle Business School, Northumbria University, Newcastle Upon Tyne, UK \\ Email: ^K.Gopalakrishna-Pillai@uea.ac.uk, C.Leonidou@leeds.ac.uk, xuemei.bian@northumbria.ac.uk
}

How to cite this paper: Pillai, K.G., Leonidou, C.N. and Bian, X.M. (2019) Let's Be Friends: National Homophily in Multicultural Newcomer Student Networks. Social Networking, 8, 16-38. https://doi.org/10.4236/sn.2019.81002

Received: October 31, 2018

Accepted: December 18, 2018

Published: December 21, 2018

Copyright (C) 2019 by authors and Scientific Research Publishing Inc. This work is licensed under the Creative Commons Attribution International License (CC BY 4.0).

http://creativecommons.org/licenses/by/4.0/

(c) (i) Open Access

\begin{abstract}
Understanding the relational and network dynamics among newcomer networks is important to devising appropriate strategies that will maximize the productivity of the incoming workforce. Nevertheless, there are limited empirical contributions on newcomer networks with few studies examining newcomer networks in international environments. This study focuses on national homophily and examines whether ethnic identity salience, self-efficacy, individualism and ethnocentrism are associated with the occurrence of national homophily in newcomers networks. Using a multicultural student sample drawn from newly formed networks, the study found that ethnic identity salience and academic self-efficacy are associated with national homophily positively and negatively, respectively. Individualism is not found to be related to homophily while, contrary to our hypothesis, ethnocentrism is found to be negatively related to homophily. Through its examination of the effect of attitudinal variables on homophily, this study contributes to the broader literature on homophily and provides implications for managers and researchers.
\end{abstract}

\section{Keywords}

Homophily, Newcomer Networks, Interpersonal Relationships, Nationality

"The people with whom we interact ... influence our belief, decisions and behaviors". [1] (p. 1).

\section{Introduction}

Globalization of the labor force has been increasing in recent years. This is particularly evident in the managerial talent pool, especially among global majors. 
These companies hire new recruits from leading business schools around the world. The newcomers in these companies, consequently, have been increasingly global and multicultural. Understanding the relational and network dynamics in these newcomer networks is important to devising appropriate strategies that will maximize the productivity of the incoming workforce. Extant literature focusing on when and if individuals form networks and associated outcomes informs us of the dynamics and processes inherent in such networks as well as their effects on individuals and organizations' performance ([2] [3] [4]). These streams of literature largely examine established networks comprising old and some new members. The growing body of multicultural newcomer networks, mentioned above, calls for a better understanding of the specific processes and characteristic of such networks. Though there exist studies on migrant networks (e.g., [5] [6]), only a few studies in management have examined newcomer social networks (e.g. [7]), and little research has examined multicultural newcomer networks. This study contributes to a better understanding of such networks.

In this study, we examine national homophily in multicultural newcomer networks. Homophily is the "tendency for people to associate with others similar to them in terms of attributes (e.g., race, gender) and values" ([7], p. 123; see also [8]). Sociologists have examined homophily in different contexts, such as schools, workplaces and voluntary organizations ([9]). Prior research in management has examined gender based ([10]) and racial homophily ([11] [12]), while sociological research has recorded evidence of ethnic homophily ([13] [14]) in organizations. Mollica et al. [7] examined racial homophily in newcomer networks and found that racial minorities exhibited greater homophily compared to whites. Studies have not examined ethnic or national homophily in newcomer networks. Understanding this issue is important as global majors recruit significant numbers of postgraduate students from countries such as China, India, and Brazil, which provides an increasingly substantial context for national homophily in newcomer networks. In this study, we employ a multicultural student sample drawn from newly formed cohorts and examine the antecedent effects of ethnic identity salience, academic self-efficacy, individualism, and ethnocentrismon homophily. Much of the work on homophily has adopted a structural perspective ([9]) and there has been a dearth of research on psychological and attitudinal antecedents of homophily. Through its examination of the effect of attitudinal variables on homophily, this study also contributes to the broader literature on homophily.

The next section briefly outlines the literature on homophily. The hypotheses are then developed. Subsequently, the method is described and the results that demonstrate the antecedent effects of ethnic identity salience and academic self-efficacy on national homophily are discussed. The paper concludes with a discussion of implications of the findings for research and practice.

\section{Literature Review}

Homophily refers to the affinity towards similar others. Sociological enquiry on 
homophily started with the examination of small groups. Early studies, thus, focused on schools, colleges, and small urban neighborhoods ([9]). These studies demonstrated the prevalence of homophily primarily on the basis of demographic factors ([15]). Later studies utilized large-scale surveys and more sophisticated network analysis techniques to examine homophily ([16] [17]). The study of homophily in organizational contexts is of relatively recent origin ([10] [18]).

Previous research in management has examined gender and racial homophily in organizational contexts ([7] [10] [11] [12] [19] [20]). Of interest to this study, [7] found that minorities exhibited greater homophily compared to whites in newcomer networks. These researchers used a student sample to investigate homophily in newcomer networks. They also found that homophilous tendencies were relatively stable among students, over a period of time, despite the promotion of diversity and heterogeneity in an educational setting, such as multiracial groups. Other researchers, too, have examined racial homophily in organizations ([11] [12] [21]). For example, [21] found an inverse relationship between the proportion of people who are racially different, and the prevalence of supportive relations among whites and blacks.

Ibarra [10] studied gender based homophily and found that men had a greater likelihood of forming stronger homophilous ties, as well as forming such ties across diverse networks, compared to women. More recent research on gender homophily has found that aspects such as job functions, office buildings and semiformal organizational structure can strengthen the effect of gender homophily on communication in an organizational setting ([19]). According to [10], two theoretical perspectives can explain homophily. While the first focuses on an individual's preferences to relate to others who are similar, based on theories of interpersonal attraction ([22]), the second provides a structural perspective that focuses on the availability of possible relationships that, in turn, determine the individual's preferences ([23]).

Studies have argued for positive and negative effects of homophilous ties in organizations. On the one hand, these act as social support mechanisms ([11] [24]), improve communication, and enhance trust and reciprocity in relationships ([7] [11]). These positive effects can be particularly useful during phases characterized by uncertainty and novelty, as is obtained in newcomer networks. On the other hand, when individuals with similar background characteristics (e.g., age, gender, nationality) develop their own subgroups, the benefits of functional diversity in an organization might be negated due to the lack of contact of individuals with diverse others ([25]). Hence, understanding the role of homophilous ties within newcomer networks is important.

Simultaneously, homophily can have a restricting effect on one's social world that, in turn, affects the nature and extent of information that individuals receive, the beliefs and attitudes that individuals form and the quality of interactions that people experience ([9]) which underscores the need to study homophily in new contexts. These authors also note that race and ethnicity have the potential to create the strongest divide in a social context. Though studies have 
examined racial homophily in organizational contexts ([11] [12]), the investigation of ethnic homophily in organizations has received scant attention, barring a few studies by sociologists ([13] [14]). It should be noted that national homophily largely corresponds with ethnic homophily, especially in a student group comprising students from Asia, Europe, and Africa. Evidence of the convergence of ethnic and national identity labels can be found in the work of [26]. Around $60 \%$ of the ethnic labels chosen by a sample of ninth grade students in Los Angeles corresponded to national identity. This figure would increase substantially if hyphenated labels (e.g., Asian-American), a characteristic of American society, were excluded. Therefore, this study, through its investigation of national homophily, adds to the body of work on ethnic homophily. McPherson et al. [9] (p. 145) also call for more research on the "impact of multiplex ties on the patterns of homophily". Newcomer networks afford the possibility of multiplex ties as actors are linked in several ways (e.g., batch mates, friends, project mates). Thus, the present study responds to this call.

As noted by [9], prior research has primarily sought to examine the causal role of structural sources on homophily. Geography, family ties, organizational foci, occupational roles and other variables provided an explanation for the occurrence of homophilic tendencies, whether they are gender, age, race, ethnicity, religion, or social class based. Recent research has studied the effect of attitudinal variables on homophily. For example, [27] reported that a need for closure affects individuals' perception of homophily within a network. Mollica et al. [7] found that racial identity salience leads to racial homophily. Motivated by this recent line of enquiry, we seek to understand the effects of attitudinal variables on national homophily in newcomer networks. Our choice of variables was influenced by the desire to build on the findings of prior research, as well as to uncover the effects of variables that could potentially affect homophily in a newcomer network. Thus, we chose ethnic identity salience, following [7], individualism and ethnocentrism, as these can have an effect on national homophily, and academic self-efficacy as this study's context is multicultural student groups (see Figure 1).

As highlighted above, prior research has shown that ethnic and national identities have substantial overlap. We specifically chose to study national homophily as observation and informal discussion with students revealed that they form friendships and hang out with students of the same nationality. Ethnicities in University application forms are reported in broad terms (white, black etc.) which limit variability, reduce the richness of available data, and provide a less than full understanding of underlying processes. Very possibly, students' own interpretation of their ethnicities might be different. Most importantly, the scale for ethnic identity salience that we employ taps into the domains of ethnicity and culture. Aspects such as food and music, that the scale mentions, are closely linked to national identities (Chinese food, Thai food, Polish food etc), and hence the relevance of studying national homophily. In the following paragraphs, we develop the hypotheses. 


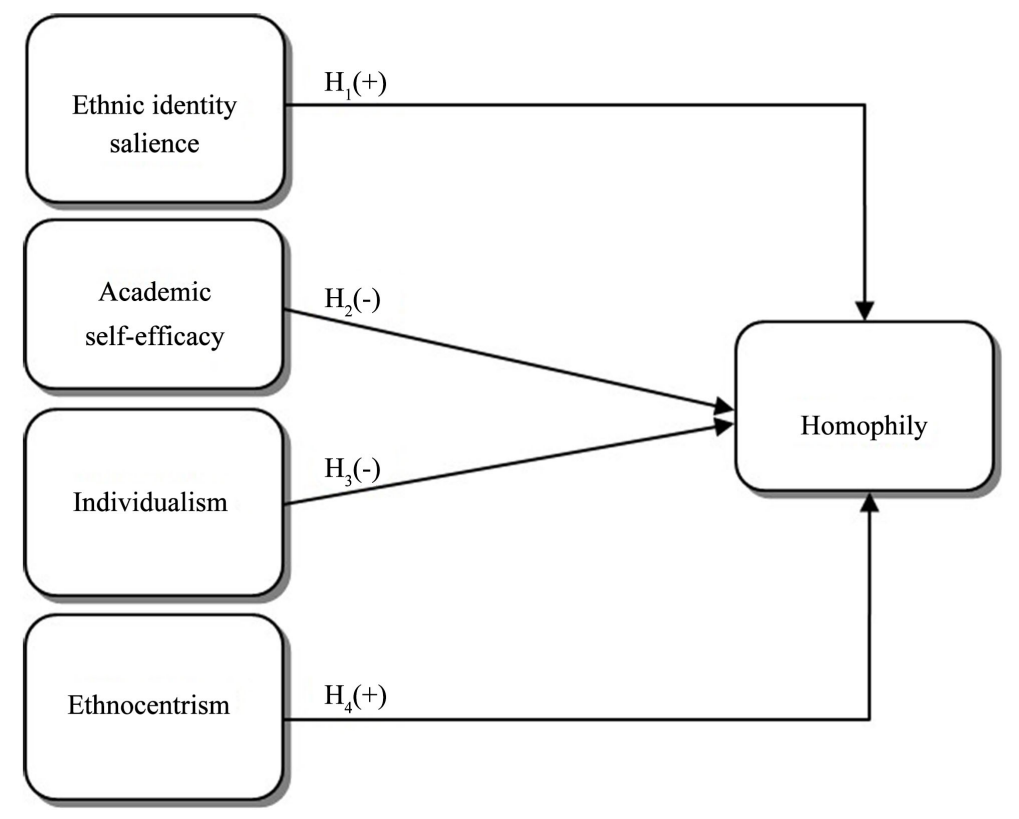

Figure 1. The conceptual model.

\subsection{Ethnic Identity Salience}

Following the discussion earlier on the substantial overlap between ethnic and national identities, especially in a multicultural student context, we focus on the antecedent effect of ethnic identity salience on national homophily. Literature on social identity has noted that individuals possess various types of social identities ([28]). Different situations and goals can render some identities salient ([29]) and a novel multicultural context has the potential to enhance the salience of ethnic and national identity for some individuals. Ethnic identity salience can be defined as the degree of importance attached to their ethnic identity by individuals, while ethnic identity salience is continuous in nature and can range from strong to weak ([30] [31]).

In her review of studies on ethnic identity, [30] (p. 194) notes that individuals who have strong ethnic identity salience identify themselves as "group members, evaluate their group positively, prefer or are comfortable with their group membership, are interested in, knowledgeable about, and committed to the group, and are involved in ethnic practices". In a multicultural newcomer context, these attitudes and characteristics will motivate individuals with strong ethnic identity salience to forge close ties with others of the same ethnic identity. Therefore, given the overlap between ethnic and national identities, a strong ethnic identity will manifest in national homophily. It has also been noted that ethnic identity concerns itself with "intergroup boundary maintenance" ([31] p. 51). Such an attitude will lead to perception of others as belonging to ingroup and outgroup, with consequent behavioral manifestations of approach towards the ingroup and avoidance of the outgroup. Since the ingroup comprises people of the same ethnicity and nationality, this will also drive homophilic tendencies. Hence, we hypothesize that: 
Hypothesis 1: In a multicultural newcomer context, ethnic identity salience is positively related to national homophily.

\subsection{Academic Self-Efficacy}

Bandura ([32], p. 3) proposed the concept of self-efficacy defined as "beliefs in one's capabilities to organize and execute the courses of action required to produce given attainments". That is, self-efficacy is a person's belief in his or her ability to perform well and succeed in specific situations. Thus, self-efficacy beliefs are concerned less with the skills and competencies that individuals possess and more with what they believe they could accomplish with the skills and competencies they possess. Bandura ([33] [34]) emphasized that mastery and vicarious experiences are critical to the development of self-efficacy.

Scholars have sought to apply the construct to the academic domain, leading to the espousal of academic self-efficacy ([35]). This concerns individuals' beliefs about their ability to perform specific academic tasks at designated levels ([35]). Family, peer influences, schooling and other transitional factors contribute to the development of academic self-efficacy ([36]). Researchers have noted that academic self-efficacy is an antecedent of the development of self-concept ([37]).

Studies have recorded the influence of self-efficacy on persistence, effort and achievement ([32] [38]). In an organizational context, task performance demands ties with diverse others. For example, in an academic context, successful completion of projects demands smooth relationships with project mates who are likely to be from other cultures, as well as interactions with other students to enhance learning. This is especially so when the student invariably finds him/herself in multicultural project groups, as is obtained in the universities from which data were collected for this study. Motivated by the desire to maximize performance, students high in academic self-efficacy are likely to form ties with several others from other cultures, compared to those who are low in academic self-efficacy. Therefore, academic self-efficacy will be negatively related to national homophily.

Scholars examining the development of self-efficacy have noted that parents who instruct children how to cope with obstacles and difficulties strengthen children's self-efficacy ([36]). In turn, self-efficacious children will be able to cope with difficulties and challenges better. Faced with the challenges of a multicultural newcomer scenario, those with enhanced self-efficacy beliefs will be more adept at overcoming the challenges through proactive actions including forming new ties with significant others. It has also been noted that prior experiences contribute to the development of self-efficacy ([33] [34]). Those high in academic self-efficacy are more likely to have engaged in fruitful collaborative efforts that contributed to their success and, therefore, will be more adept at forming connections with a range of significant others that are important to their academic performance. Hence academic self-efficacy will be positively related to national heterophily and negatively to homophily. 
Hypothesis 2: In a multicultural student newcomer context, academic self-efficacy is negatively related to national homophily.

\subsection{Individualism}

Individualism can be defined as the principle of being independent, unique, and self-reliant ([39]). Independence emphasises an individual's value of autonomy in judgment, decision making, and actions ([40] [41]). Hollander ([42]) highlights the importance of independence, in which one acts in accord with personal beliefs and values rather than responding in terms of other people's judgments or preference. Independent responses represent an active individual choice instead of merely a reaction to the choices of others, thus are not an automatically different approach as is the case with anticonformity. For high independent individuals, the self is perceived as equal in status to others, whereas for low independent individuals the self is perceived as different from others ([43]). High independent individuals are more likely to challenge hierarchically structured power and status distribution and calls for establishing egalitarian relations between people of different status and qualities ([44]). Low independent individuals, in contrast, embrace hierarchically structured power distribution with a sharp differentiation between those with and without power ([45]). The pursuit of egalitarianism and equality are likely to lead high independent individuals to establish ties with out-group members but less likely to focus on establishing and embracing in-group ties, compared to low independent individuals. Low independent individuals, in contrast, might be more motivated to interact with in-group counterparts, for example individuals of the same national background in a multinational context, which results in a higher level of national homophily.

Uniqueness reflects the importance of developing one's unique identity and expressing characteristics that are different from others ([40] [43]). Uniqueness theory ([46]) states that people are motivated to maintain a sense of specialness. Different individuals evidence varying degrees of uniqueness motivation ([47]). Individuals may fulfil their desire to be unique in a variety of ways, for example through possession displays ([48]), consumer behaviours and possessions ([49]), the domains of knowledge in which they establish expertise ([50]), and also of particular interest to this study, interpersonal interaction ([49]).

Individuals of high uniqueness enjoy being unique and different from others in many ways and often do their own thing ([51]) which, consequently, would show less tendency of forming social ties ([52]), including national ties and cross-national ties. Salient identity and personality literature lends support to this argument suggesting that being unique also has the connotation of being different and distinctive, and of establishing and protecting one's own identity and individuality ([53] [54]). Individuals of low uniqueness, in contrast, perceive themselves being more or less similar to others. Prior studies show that perceived similarity (value and personality traits) predicts higher attraction to strangers ([55]) and higher friendship intensity ([56]). Thus, it is likely that in- 
dividuals of low uniqueness are more likely to cultivate friendship ties. The present study predicts that compared with individuals of low uniqueness, individuals of high uniqueness are less likely to form national ties in a context of multinational newcomers. Given both uniqueness and independence dimension of individualism indicates a negative relationship with national homophily in a multinational newcomer context, the following hypothesis is offered:

Hypothesis 3: In a multicultural newcomer context, individualism is negatively related to national homophily.

\subsection{Ethnocentrism}

Sumner ([57], p. 13) introduced the construct of ethnocentrism which is defined as the "technical name for this view of things in which one's own group is the center of everything, and all others are scaled and rated with reference to it". Ethnocentrism leads to a distinction between ingroup and outgroup, with a consequent favorable attitude to the ingroup and an unfavorable attitude to the outgroup ([57] [58]). As Sumner notes "each group nourishes its own pride and vanity, boasts itself superior, exalts its own divinities, and looks with contempt on outsiders" ([57], p. 12). The ingroup is often nationally defined ([59]) and the construct has been useful in understanding conflicts between ethnic and national groups ([58] [60]). Ethnocentrism can lead to stereotypical perceptions of outgroup members, followed by hostility, and a strong emotional attachment to ingroup members ([58] [60]).

Social psychologists have noted that ethnocentrism results when individuals categorize themselves into groups that are emotionally relevant and significant ([60]). This, in turn, leads to an exaggeration of between group differences and a minimization of within group differences ([58] [62]). Underlying this process is a desire for "positive distinctiveness" as noted by [63]. Individuals will desire a sense of worth and pride that arises from a view that "my group is better than other groups" ([58] [61]). This will lead to behavioral manifestation of homophily. Based on the above arguments, we reason that ethnocentrism leads to interpersonal affinity towards people from the same country. Therefore, ethnocentrism will lead to national homophily.

Hypothesis 4: In a multicultural newcomer context, ethnocentrism is positively related to national homophily.

\section{Method}

\subsection{Research Context and Sample}

The context of the study was multicultural students enrolled in postgraduate management programs. Prior research on friendship formation and newcomer social networks has employed student samples ([7] [64] [65] [66]). Though we collected data from an academic setting, the fact that several students enroll for postgraduate studies after some work experience, as well as the pedagogical format which emphasizes group work and assignments, ensures that the scenario 
approximates an organizational newcomer context.

The study took place in two British universities among full-time students studying in nine postgraduate programs (e.g., MA Advertising and Marketing; MSc Finance; MSc Management). These students came from very diverse ethnic and national backgrounds and, for many, studying in a British higher education institution was considered as a new experience. All students enrolled in these programs were invited to participate in this study midway through the first semester of teaching. This helped us to focus on a newly formed network in which all students were considered as "newcomers", while at the same time allowing for sufficient time for new friendships to be shaped.

The data collection took place in two phases lasting, altogether, four months. A cover letter explaining the purpose of this research and the study questionnaire were prepared and distributed to every student in each program during scheduled classes. Respondents were asked to complete the questionnaire in their own time and return this to the project coordinator or drop it into a specially designed survey box. Students were informed that participation was voluntary and that data would be kept confidential. Two reminder emails containing an electronic version of the questionnaire followed in order to remind students about the study and boost response. To further encourage participation, students were promised incentives such as Amazon coupons. From the total number of students studying in each program (i.e., 873 students), 195 completed questionnaires were returned representing a $22.3 \%$ response rate. Of those, only 182 were adequately and fully completed for the purposes of the study.

In terms of demographic characteristics, the final sample was not equally split between males $(26.9 \%)$ and females $(73.1 \%)$, primarily attributed to the high enrollment rate of female students in the business school programs used in this study. More than half of the respondents (68.7\%) were in the 19 - 24 age group, $29.7 \%$ were between 25 and 34 years old, while a small percentage (1.6\%) were mature students (35 - 44). With regard to annual household income, more than half of the sample (52.1\%) earned less than UK£20,000, another $18.6 \%$ had an income ranging from UK£20,000 to UK£29,999, around a tenth of the sample $(10.8 \%)$ between $U K £ 30,000$ to $U K £ 39,000$, and the remainder $(18.5 \%)$ $\mathrm{UK} £ 40,000$ or more. In terms of the nationality of the respondents, $32.4 \%$ were Chinese, 9.3\% British, 8.8\% Taiwanese, 6.0\% Thai, 4.4\% Greek, 3.3\% were Indian, $3.3 \%$ Nigerian, while the remaining sample $(32.5 \%)$ originated from countries such as Russia, Vietnam, Malaysia, Indonesia, Canada, USA, and Italy.

Three tests were conducted to check for the existence of possible non-response bias in the sample. First, the available student demographics between respondents and non-respondents were compared and contrasted. Second, the answers of respondents from the first phase were compared to those of the second phase. Third, the answers of early respondents $(n=25)$ were compared to those of late respondents $(n=25)([67])$. All three tests revealed no statistically significant differences between the groups compared. These findings indicate the non-response bias is unlikely to be a concern in this study. 


\subsection{Measures}

The study used a structured questionnaire as the research instrument. This was carefully developed and pretested with nine students to ensure that it had an appropriate flow, clarity, and length. A detailed list of the study's main constructs and items can be found in the Appendix. Four different antecedent constructs were used in the model, the scales of which were extracted after a careful review of the pertinent literature, as follows: identity salience was operationalized using the scale proposed by [68] assessing various aspects of an individual's ethnic identity; academicself-efficacy was based on the measure of [69] and reflected the respondents' confidence in their ability to perform well academically; the individualism scale was based on [70] and [51] and measured the respondents' belief in an independent self, who is unique, autonomous and different from other people; and ethnocentrism was operationalized using the four highest-loading items from [71] measuring respondents' opinions regarding purchasing foreignor domestically-produced goods. All constructs were measured using a 7-point Likert scale ( 1 = strongly disagree; 7 = strongly agree).

Dummy variables were created for the controls in the model. Specifically, gender $(0=$ female; $1=$ male $)$, marital status $(0=$ single; $1=$ married $/$ long term relationship), postgraduate program type $(0=$ non-marketing program; $1=$ marketing program), and nationality of the students. Given the large number of nationalities in the dataset, we controlled for the two largest groups by creating three dummies, namely Chinese, British, and other.

The literature has employed several measures of homophily. We sought to measure national homophily using the formula for inbreeding homophily provided by [72]. This measure, "normalizes the homophily index by the potential extent to which a group could be biased" ([72], p. 1008). Inbreeding homophily, to clarify, is the homophily observed above baseline homophily. Baseline homophily is found when the ratio noted above (same nationality ties as a proportion of total ties) is equal to the ratio of that particular nationality people (same nationality people as a proportion of total number of people). The index takes the value of 1 when there is complete inbreeding homophily. A value of zero indicates baseline homophily and the negative value indicates heterophily. Though [72] employed the formula to study homophily at the group level (unit of analysis was the different races), the formula is equally suited to study homophily at the individual level, as in the case of this study ${ }^{1}$.

In order to capture homophily, participants were provided with a roster which included all student names enrolled in their particular postgraduate program in alphabetical order. The students were asked to check off the names of students that were considered as friends ([10]). Subsequently, in each case we noted down the number of friend cites involving same nationality students. As mentioned

${ }^{1}$ This was verified through personal communication (28 August 2014) with Matthew O. Jackson (Stanford University), one of the co-authors of the [72] article from which the homophily formula was adopted. 
above, we used a formula that controls reported national homophily ties for the availability of same nationality ties as a function of group size (see [72]). The formula is as follows:

$$
H=\frac{\left(\frac{s_{i}}{s_{i}+d_{i}}\right)-w_{i}}{1-w_{i}}
$$

where $s_{i}$ is the number of same nationality ties a person cited, $d_{i}$ the number of cross-nationality ties a person cited, and $w_{i}$ is the number of same nationality individuals divided by the total number of individuals.

\subsection{Common Method Bias}

Because all data came from a single cross-sectional survey the potential of common method bias exists. To address this issue in the study we followed Podsakoff and associates' [73] steps for minimizing and checking the effects of common method bias. First, we employed several ex anteprocedural remedies such as guaranteed anonymity to all respondents, reduced apprehension by assuring subjects that there was no right or wrong answer, and careful construction and checking of the study measures with the input of two academic experts on the subject. In addition, we chose a formula-based scale for measuring the dependent variable (i.e., homophily) that is complex in nature and prevented respondents from guessing the relationship between predictor and criterion constructs.

Second, we conducted two ex post statistical tests. Specifically, we applied the [74] one-factor test, whereby all study items were inserted into an exploratory factor analysis. No single factor emerged that explained the variance across all items identified, while the first factor explained only $21 \%$ of the total variance. In addition, using a procedure suggested by [75] and [76], a common method factor was included in the statistical model to reflect the shared variance of all constructs in the model. The common method factor was allowed to load on the manifest indicators, but no correlations were specified between common method factor and any other variables. The results pertaining to the study's hypotheses were stable in the model in which the common method was present, while none of the common method factor loadings were significant. Collectively, these findings provide additional confidence that our study is free from common method bias.

\subsection{Social Desirability Bias}

In addition, due to the sensitive nature of this topic (i.e., forming and nurturing friendships), there was a possibility of certain types of students (i.e., those with Asperger's syndrome) experiencing emotional stress and answering survey questions in a socially desirable way. To minimize the possibility, the following text appeared immediately before the friendship question: "We understand that each person is very different in terms of personality and social networking. Some might not have as many friends as others, while some others might prefer to 
completely avoid forming friendships during the course. So please complete this task in an honest way because only then we would be able to extract safe conclusions from the study." We also used the social desirability bias scales provided by [77] to check for this in a post hoc way. No significant bivariate correlations (at $p<0.10$ ) were found between these scales with any of the study's constructs, suggesting that social desirability bias is not a problem in this study.

\section{Data Analysis and Results}

We used SmartPLS 3.2.1 ([78]) to analyze our data and test the research hypotheses. Partial Least Squares (PLS) is a structural equation modeling technique based on an iterative estimation algorithm, comprising a series of ordinary least square (OLS) regression analyses ([79]). This is an increasingly popular technique utilized in organizational and relationships-based research (e.g., [80]). We chose this technique because of its effectiveness as there are no identification issues involved, and generally high levels of statistical power can be achieved even in cases with a small sample size (i.e., $n<200)([81])$. In addition, the technique is very stable since improper or non-convergent solutions are unlikely to occur, and highly reliable because its bootstrapping capabilities can provide robust results ([82]).

\subsection{Construct Validity and Reliability}

To evaluate the construct's psychometric properties we began analyzing the information from the outer model. Specifically, we assessed descriptive statistics, scale reliabilities, individual factor item loadings, and the Average Variance Extracted (AVE) for each variable. All constructs exhibited high Cronbach's alpha (i.e., $>0.71$ ) and composite reliability (i.e., $>0.81$ ) scores indicating reliable measurement. In addition, convergent validity was evident since every item loaded highly and significantly on its theoretical construct, and all outer loading values were generally above the accepted threshold (i.e., >0.70). In two cases, item loadings were slightly below this threshold (i.e., 0.66 and 0.67 ), but the decision was made to retain these items for content validity purposes ([81]). Furthermore, the constructs exhibited high discriminant validity since the individual construct AVEs were high $(>0.50)$, and any cross-loading between items and constructs was low, while the shared correlation between every pair of construct was always dwarfed by the AVE squared root for each respective construct ([83]). Hence, the results show that the measured constructs are reliable, and have good convergent and discriminant validity.

We also followed prescriptions by network theorists to minimize reliability problems in relational data. Citing the findings of [84] who found a difference in the number of relations between free recall method and a checklist method, [85] (p. 40) suggest that "aided recall procedures-such as checklists providing cues and prompts-pose a less-serious reliability problem than free recall methods". Our use of a roster to collect relational data is expected to enhance the reliability of such data. Table 1 presents the bivariate correlation relationships between 
homophily and the four antecedent variables, while also presenting all descriptive statistics and reliabilities of the constructs.

\subsection{Hypotheses Testing}

To examine the significance of the hypothesized relationships, we estimated a structural model following a bootstrapping procedure of 5000 subsamples ([81]). The quality of the inner model was evaluated by checking the number of significant hypothesized associations, the percentage of variance explained of the endogenous latent variables (i.e., $\mathrm{R}^{2}$ ), and the effect size for each hypothesized relationship. In this case, $50 \%$ of the hypothesized relationships were supported, the adjusted $\mathrm{R}^{2}$ exceeded the minimum threshold of 0.10 (i.e., 0.12) ([86]), while all significant effect sizes were strong (i.e., $p<0.01$ ). To examine the predictive relevance of the model, we applied the Stone-Geisser test using the blindfolding procedure ([81]). For a model to have predictive relevance, the test needs to provide values (i.e., $\mathrm{Q}^{2}$ ) greater than zero (Mitchell et al. 2014). Our model indicates adequate predictive power since the $\mathrm{Q}^{2}$ value was 0.07 . The model also exhibits satisfactory model fit as evidenced by the Standardized Root Mean Square Residual (SRMR) value of 0.06 (see [87]).

Notably, two hypotheses were accepted and two were rejected. Specifically, $\mathrm{H}_{1}$ was supported since the results revealed a significant relationship between identity salience and national homophily $(\beta=0.19, \mathrm{t}=3.15, p<0.01)$. In addition, a significant negative association was found between academic self-efficacy and national homophily $(\beta=-0.17, \mathrm{t}=-2.40, p<0.05)$ lending support to $\mathrm{H}_{2}$. In contrast, individualism was found to be unrelated to the development of homophilous ties $(\beta=0.01, \mathrm{t}=0.13, p>0.05)$, thus providing no support for $\mathrm{H}_{3}$. Finally, though ethnocentrism was found to be significantly associated with homophily $(\beta=-0.18, \mathrm{t}=-2.53, p<0.01)$, the relationship proved negative, as opposed to positive, leading us to reject $\mathrm{H}_{4}$. The model statistics, path coefficients, and the $t$ values observed from the bootstrap test are provided in Table 2.

Table 1. Descriptive statistics and correlation matrix ${ }^{\mathrm{a}}$.

\begin{tabular}{|c|c|c|c|c|c|}
\hline & 1. & 2. & 3. & 4. & 5. \\
\hline 1) Identity salience & 1 & & & & \\
\hline 2) Academic self-efficacy & 0.12 & 1 & & & \\
\hline 3) Individualism & -0.07 & $0.19^{* *}$ & 1 & & \\
\hline 4) Ethnocentrism & 0.09 & -0.06 & 0.08 & 1 & \\
\hline 5) Homophily & $0.18^{*}$ & $-0.19^{* *}$ & -0.11 & $-0.17^{*}$ & 1 \\
\hline Cronbach's alpha & 0.89 & 0.87 & 0.72 & 0.88 & - \\
\hline Composite reliability & 0.91 & 0.90 & 0.82 & 0.91 & - \\
\hline Average variance extracted & 0.59 & 0.65 & 0.54 & 0.72 & - \\
\hline Mean & 4.91 & 4.88 & 5.14 & 2.46 & 0.24 \\
\hline Standard deviation & 1.07 & 0.95 & 1.01 & 1.22 & 0.31 \\
\hline
\end{tabular}

${ }^{\mathrm{a}} \mathrm{n}=182 ;{ }^{\mathrm{b}}$ Single-item construct, ${ }^{\star} p<0.05 ;{ }^{* *} p<0.01$. 
Table 2. PLS path coefficients and results ${ }^{\mathrm{a}}$.

\begin{tabular}{|c|c|c|c|c|}
\hline Path & Hypothesis & $\begin{array}{c}\text { Path } \\
\text { coefficient }\end{array}$ & t-value & Result \\
\hline \multicolumn{5}{|l|}{ Hypothesized links } \\
\hline Identity salience $\rightarrow$ Homophily & $\mathrm{H}_{1}$ & 0.19 & $3.15^{* *}$ & Supported \\
\hline Academic self-efficacy $\rightarrow$ Homophily & $\mathrm{H}_{2}$ & -0.17 & $2.40^{*}$ & Supported \\
\hline Individualism $\rightarrow$ Homophily & $\mathrm{H}_{3}$ & 0.01 & 0.13 & Not supported \\
\hline Ethnocentrism $\rightarrow$ Homophily & $\mathrm{H}_{4}$ & -0.18 & $2.53^{* *}$ & Not supported \\
\hline \multicolumn{5}{|l|}{ Control links } \\
\hline Gender & & -0.02 & 0.29 & \\
\hline Marital status & & -0.00 & 0.04 & \\
\hline Postgraduate program type & & 0.13 & 1.89 & \\
\hline Nationality - Chinese & & 0.17 & 1.87 & \\
\hline Nationality - British & & 0.04 & 0.60 & \\
\hline $\mathrm{R}^{2}$ for Homophily & & & & 0.16 \\
\hline Adjusted $\mathrm{R}^{2}$ for Homophily & & & & 0.12 \\
\hline $\mathrm{Q}^{2}$ & & & & 0.07 \\
\hline SRMR & & & & 0.06 \\
\hline
\end{tabular}

${ }^{\star} p<0.05 ;{ }^{* *} p<0.01$.

\subsection{Additional Analysis}

While our study focused particularly on the antecedents of homophily, we were intrigued with the prospect of uncovering the pragmatic implications of homophily in newcomer networks. For this reason, we collected additional data to understand whether individual performance in class is affected by the lack of interactivity with different nationality students. Specifically, we were able to obtain the grades for 117 students from the original sample pertaining to two equal credit marketing modules; one had a groupwork element as the sole method of assessment and the other had one piece of individual essay worth $100 \%$ of the final module mark. We were also able to obtain the semester one grade average for the same number of students. We used a series of regressions using two nationality dummy variables (i.e., British and Chinese), marital status, and gender as control variables, and homophily as independent variable. The results reveal homophily as a significant negative predictor of individual (Beta $=-0.18, t=$ $-1.91 p<0.10$ ) and average student performance (Beta $=-0.23, t=-2.62 p<$ 0.01 ), but not group work student performance (Beta $=-0.13, t=-1.40 p>$ $0.10)$.

\section{Discussion and Conclusion}

The results of this study suggest that in a multicultural newcomer context indi- 
viduals who have strong ethnic identity salience tend to forge close ties with others of the same national identity and this manifests in national homophily. This finding is in accord with the findings of prior research on ethnic identity salience ([31]). In contrast, individuals high in ethnocentrism are less likely to show national homophilic tendencies. The finding in relation to ethnocentrism contradicts prior field research which found that ethnocentrism can lead to a strong emotional attachment to ingroup members and stereotypical perceptions of members of outgroups, followed by hostility and exclusion ([58] [60]). We explain this divergent finding on the basis of the measure of ethnocentrism. We employed a measure of consumer ethnocentrism that taps into attitudes towards purchasing foreign versus domestically produced products. As such, the domain specific nature of this measure might have rendered it somewhat unrelated to behavioral manifestations of friendship in a newcomer student context. This would attenuate the hypothesized positive relationship between the two constructs. Still, the negative relationship between ethnocentrism and homophily is surprising. Possibly, the relationship could be mediated by extraneous variables. For example, vested economic interests of individuals hailing from business families can lead to such individuals exhibiting strong consumer ethnocentrism, though this might not be related to general attitudes and perceptions. This contrarian finding, therefore, needs further validation before possible mechanisms are elucidated.

Another interesting finding of this study is that individuals high in academic self-efficacy are likely to form ties with others from other cultures and show less national homophilic tendencies, compared to those who are low in academic self-efficacy. Although there is limited research investigating the effect of self-efficacy on homophily, our finding is consistent with the broader literature suggesting significant influence of self-efficacy on persistence, effort and achievement ([34] [36]), and acquisition and maintenance of peer acceptance ([88]).

Individualism was hypothesized to have a negative effect on homophily. However, the study found a null effect. We conducted a subgroup analysis between high and low individualistic students (median split). We found a statistically significant difference in the total number of friendships ( $\mathrm{F}=3.276 ; p<$ 0.10 ) between the two groups. More individualistic students tend to form less friendships on average (MAverageFriendships $=11.37$ ) than students with lower individualism (MAverageFriendships $=14.43$ ). Likewise, individualistic students (MSameNationTies $=2.85)$ tend to form significantly less same nationality ties $(\mathrm{F}=11.03 ; p<0.01)$ than less individualistic students $($ MSameNationTies $=$ 5.74). It can be seen that the difference in same nationality ties is statistically stronger than the difference in total number of friendships. This indicates a directional support to our hypothesis. We also found that our sample is limited in terms of individualism responses as most of the responses seem to be more than 4.00 and only 19 cases fall below this mark. Thus, though our reasoning seems to 
work, the restricted variance resulted in a statistically non-significant result. It is possible that studying abroad itself is correlated with individualism. Future research can examine this issue further and expand the investigation to cover other contexts where more variance in individualism can be obtained.

The finding that academic self-efficacy is negatively related to homophily can be extended to organizational contexts-self-efficacy has an inverse relationship with homophily in organizational multi-cultural newcomer contexts. This implies that measuring the self-efficacy beliefs of newcomers will enable organizations to manage homophily. Similarly, prior research has noted that identity salience can be manipulated ([29]). Organizations can manage identity salience of newcomers to influence national homophilic tendencies.

A large body of literature has documented dynamics and processes inherent in networks ([2] [3] [4]). Our review of the literature identified three research gaps which demand further research attention. First, limited research exists that throws light on the specific characteristics of multicultural newcomer networks, since existing literature mainly examines established networks comprising old and new members. Second, few studies have examined ethnic or national homophily in newcomer networks. Third, understanding of the effect of attitudinal variables on homophily remains scarce. The current study addresses these gaps and adds to the existing literature on homophily by examining the attitudinal antecedents of national homophilic tendencies in a multi-cultural context.

Future research can further investigate the role of attitudinal variables in homophily, especially in newcomer networks and, in particular, in multicultural newcomer networks. Given the limited research on multicultural newcomer networks and the increasing prevalence of these networks in global companies, scholars can study the effect of demographic and psychological characteristics, too, on homophily in these contexts. Future research can also investigate the role of moderators of the relationships proposed in this study. Research can extend the enquiry to social capital in multicultural newcomer networks, including its drawbacks ([89]). Finally, a limitation of the current study is that data were collected from a student population. Future research can replicate the findings using multicultural newcomer samples in organizations.

Understanding patterns of interactions can help integrate newcomers into new social and work environments, especially those individuals who might face integration problems because of language, culture, and identity barriers ([64]). Unlocking the dynamic processes in newcomer networks, and especially in multicultural environments, affords organizations the opportunity to introduce the right incentives and policies aimed at fostering productivity and excellence while creating equality of opportunities. We believe the current study is a building block in this increasingly important and useful stream of research.

\section{Acknowledgements}

The authors thank Matthew O. Jackson (Stanford University) for his construc- 
tive comments and suggestions.

\section{Conflicts of Interest}

The authors declare no conflicts of interest regarding the publication of this paper.

\section{References}

[1] Jackson, M. (2010) An Overview of Social Networks and Economic Applications. In: Benhabib, J., Bisin, A. and Jackson, M., Eds., Handbook of Social Economics, North Holland.

[2] Burt, R.S. (1992) Structural Holes. Harvard University Press, Cambridge.

[3] Coleman, J.S. (1990) Foundations of Social Theory. Harvard University Press, Cambridge.

[4] Gulati, R. (1998) Alliances and Networks. Strategic Management Journal, 19, 293-317. https://doi.org/10.1002/(SICI)1097-0266(199804)19:4<293::AID-SMJ982>3.0.CO;2$\underline{M}$

[5] Chen, W. (2015) Mediatizing the Network Model of Cultural Capital: Network Diversity, Media Use, and Cultural Knowledge Along and Across Ethnic Boundaries. Social Networks, 40, 185-196. https://doi.org/10.1016/j.socnet.2014.10.003

[6] Lubbers, M.J., Molina, J.L., Lerner, J., Brandes, U., Ávila, J. and McCarty, C. (2010) Longitudinal Analysis of Personal Networks. The Case of Argentinean Migrants in Spain. Social Networks, 32, 91-104. https://doi.org/10.1016/j.socnet.2009.05.001

[7] Mollica, K.A., Gray, B. and Trevino, L.K. (2003) Racial Homophily and Its Persistence in Newcomers' Social Networks. Organization Science, 14, 123-136. https://doi.org/10.1287/orsc.14.2.123.14994

[8] Lazarsfeld, P. and Merton, R.K. (1954) Friendship as a Social Process: A Substantive and Methodological Analysis. In: Berger, M., Abel, T. and Charles, H., Eds., Freedom and Control in Modern Society, Van Nostrand, New York.

[9] McPherson, J.M., Smith-Lovin, L. and Cook, J. (2001) Birds of a Feather: Homophily in Social Networks. Annual Review of Sociology, 27, 415-444. https://doi.org/10.1146/annurev.soc.27.1.415

[10] Ibarra, H. (1992) Homophily and Differential Returns: Sex Differences in Network Structure and Access in an Advertising Firm. Administrative Science Quarterly, 37, 422-447. https://doi.org/10.2307/2393451

[11] Ibarra, H. (1993) Network Centrality, Power, and Innovation Involvement: Determinants of Technical and Administrative Roles. Academy of Management Journal, 36, 471-501.

[12] Mehra, A., Kilduff, M. and Brass, D.J. (1998) At the Margins: A Distinctiveness Approach to the Social Identity and Social Networks of Underrepresented Groups. Academy of Management Journal, 41, 441-452.

[13] Kalleberg, A.L., Knoke, D., Marsden, P.V. and Spaeth, J.L. (1996) Organizations in America: A Portrait of Their Structures and Human Resources Practices. Sage, Newbury Park.

[14] Reskin, B. (1999) Occupational Segregation by Race and Ethnicity among Women Workers. In: Browne, I., Ed., Latinas and African American Women at Work. Race, Gender, and Economic Inequality, Russell Sage Foundation, New York.

[15] Loomis, C.P. (1946) Political and Occupational Cleavages in a Hanoverian Village, 
Germany. Sociometry, 9, 316-333. https://doi.org/10.2307/2785496

[16] Laumann, E.O. (1973) Bonds of Pluralism: The Form and Substance of Urban Social Networks. Wiley, New York.

[17] Shrum, W., Cheek Jr., N.H. and Hunter, S.M. (1988) Friendship in School: Gender and Racial Homophily. Sociology of Education, 61, 227-239. https://doi.org/10.2307/2112441

[18] Reuf, M., Aldrich, H.E. and Carter, N.M. (2003) The Structure of Founding Teams: Homophily, Strong Ties and Isolation among US Entrepreneurs. American Sociological Review, 68, 195-222. https://doi.org/10.2307/1519766

[19] Kleinbaum, A.M., Stuart, T.E. and Tushman, M.L. (2013) Discretion within Constraint: Homophily and Structure in a Formal Organisation. Organisation Science, 24, 1316-1336. https://doi.org/10.1287/orsc.1120.0804

[20] Pearce, J.L. and Xu, Q.J. (2012) Rating Performance or Contesting Status: Evidence Against the Homophily Explanation for Supervisor Demographic Skew in Performance Ratings. Organization Science, 23, 373-385.

https://doi.org/10.1287/orsc.1100.0585

[21] Bacharach, S.B., Bamberger, P.A. and Vashdi, D. (2005) Diversity and Homophily at Work: Supportive Relations among White and African-American Peers. Academy of Management Journal, 48, 619-644. https://doi.org/10.5465/amj.2005.17843942

[22] Marsden, P.V. (1988) Homogeneity in Confiding Relations. Social Networks, 10, 57-76. https://doi.org/10.1016/0378-8733(88)90010-X

[23] Blau, P.M. (1977) Inequality and Heterogeneity. Free Press, New York.

[24] James, E.H. (2000) Race-Related Differences in Promotions and Support: Underlying Effects of Human and Social Capital. Organization Science, 11, 493-508. https://doi.org/10.1287/orsc.11.5.493.15202

[25] Schneider, S.K. and Northcraft, G.B. (1999) Three Social Dilemmas of Workforce Diversity in Organizations: A Social Identity Perspective. Human Relations, 52, 1445-1467. https://doi.org/10.1177/001872679905201105

[26] Fuligni, A.J., Witkow, M. and Garcia, C. (2005) Ethnic Identity and the Academic Adjustment of Adolescents from Mexican, Chinese, and European Backgrounds. Developmental Psychology, 41, 799-811. https://doi.org/10.1037/0012-1649.41.5.799

[27] Flynn, F., Reagans, R. and Guillory, L. (2010) Do You Two Know Each Other? Transitivity, Homophily, and the Need for (Network) Closure. Journal of Personality and Social Psychology, 99, 855-869. https://doi.org/10.1037/a0020961

[28] Hewstone, M. (1996) Contact and Categorization: Social Psychological Interventions to Change Intergroup Relations. In: Macrae, C.N., Stangor, C. and Hewstone, H.H., Eds., Stereotypes and Stereotyping, Guilford Press, New York, 394-418.

[29] Shih, M., Pittinsky, T.L. and Ambady, N. (1999) Stereotype Susceptibility: Identity Salience and Shifts in Quantitative Performance. Psychological Science, 10, 80-83. https://doi.org/10.1111/1467-9280.00111

[30] Phinney, J.S. (1991) Ethnic Identity and Self-Esteem: A Review and Integration. Hispanic Journal of Behavioral Sciences, 13, 193-208. https://doi.org/10.1177/07399863910132005

[31] Ting-Toomey, S., Yee-Jung, K., Shapiro, R., Garcia, W., Wright, T. and Oetzel, J.G. (2000) Cultural/Ethnic Identity Salience and Conflict Styles. International Journal of Intercultural Relations, 23, 47-81. https://doi.org/10.1016/S0147-1767(99)00023-1 
[32] Bandura, A. (1977) Self-Efficacy: Toward a Unifying Theory of Behavioral Change. Psychological Review, 84, 191-215. https://doi.org/10.1037/0033-295X.84.2.191

[33] Bandura, A. (1986) Social Foundations of Thought and Action: A Social Cognitive Theory. Prentice-Hall, Englewood Cliffs.

[34] Bandura, A. (1997) Self-Efficacy: The Exercise of Control. Freeman, New York.

[35] Schunk, D.H. (1991) Learning Theories: An Educational Perspective. Macmillan Publishing Co., New York.

[36] Schunk, D.H. and Pajares, F. (2002) The Development of Academic Self-Efficacy. In: Wigfield, A. and Eccles, J., Eds., Development of Achievement Motivation, Academic Press, San Diego, 15-31.

[37] Bong, M. and Skaalvik, E.M. (2003) Academic Self-Concept and Self-Efficacy: How Different Are They Really. Educational Psychology Review, 15, 1-40. https://doi.org/10.1023/A:1021302408382

[38] Schunk, D.H. (1995) Self-Efficacy and Education and Instruction. In: Maddux, J.E., Ed., Self-Efficacy, Adaptation, and Adjustment: Theory, Research, and Application, Plenum Press, New York, 281-303. https://doi.org/10.1007/978-1-4419-6868-5_10

[39] Chen, F.F. and West, S.G. (2008) Measuring Individualism and Collectivism: The Importance of Considering Differential Components, Reference Groups, and Measurement Invariance. Journal of Research in Personality, 42, 259-294. https://doi.org/10.1016/j.jrp.2007.05.006

[40] Markus, H.R. and Kitayama, S. (1991) Culture and Self: Implications for Cognition, Emotion, and Motivation. Psychological Review, 98, 224-253. https://doi.org/10.1037/0033-295X.98.2.224

[41] Triandis, H.C. (1989) The Self and Social Behavior in Differing Cultural Contexts. Psychological Review, 96, 506-520. https://doi.org/10.1037/0033-295X.96.3.506

[42] Hollander, E.P. (1975) Independence, Conformity, and Civil Liberties: Some Implications from Social Psychological Research. Journal of Social Issues, 31, 55-67. https://doi.org/10.1111/j.1540-4560.1975.tb00759.x

[43] Singelis, T.M., Triandis, H.C., Bhawuk, D. and Gelfand, M.J. (1995) Horizontal and Vertical Dimensions of Individualism and Collectivism: A Theoretical and Measurement Refinement. Cross-Cultural Research, 29, 240-275. https://doi.org/10.1177/106939719502900302

[44] Schwartz, S.H. (1994) Beyond Individualism/Collectivism: New Cultural Dimensions of Values. In: Kim, U., Traindis, H.C., Kagitcibasi, C., Choi, S. and Yoon, G., Eds., Individualism and Collectivism: Theory, Method, and Application, Sage, Thousand Oaks, 81-119.

[45] Hofstede, G. (1997) Culture and Organization: Software of the Mind. McGraw-Hill, New York.

[46] Snyder, C.R. and Fromkin, H.L. (1980) Uniqueness: The Human Pursuit of Difference. Plenum Press, New York. https://doi.org/10.1007/978-1-4684-3659-4

[47] Snyder, C.R. and Fromkin, H.L. (1977) Abnormality as a Positive Characteristic: The Development and Validation of a Scale Measuring Need for Uniqueness. Journal of Abnormal Psychology, 86, 18-527. https://doi.org/10.1037/0021-843X.86.5.518

[48] Belk, R.W. (1988) Possessions and the Extended Self. Journal of Consumer Research, 15, 139-168. https://doi.org/10.1086/209154

[49] Maslach, C., Stapp, J. and Santee, R.T. (1985) Individuation: Conceptual Analysis 
and Assessment. Journal of Personality and Social Psychology, 49, 729-738. https://doi.org/10.1037/0022-3514.49.3.729

[50] Holt, D.B. (1995) How Consumers Consume: A Typology of Consumption Practices. Journal of Consumer Research, 22, 1-16. https://doi.org/10.1086/209431

[51] Sivadas, E., Bruvold, N.T. and Nelson, M.R. (2008) A Reduced Version of the Horizontal and Vertical Individualism and Collectivism Scale: A Four-Country Assessment. Journal of Business Research, 61, 201-210. https://doi.org/10.1016/j.jbusres.2007.06.016

[52] Ramamoorthy, N. and Flood, P.C. (2004) Individualism/Collectivism, Perceived Task Interdependence and Teamwork Attitudes among Irish Blue-Collar Employees: A Test of the Main and Moderating Effects? Human Relations, 57, 347-366. https://doi.org/10.1177/0018726704043274

[53] Allport, G.W. (1961) Pattern and Growth in Personality. Holt, Rinehart and Winston, New York.

[54] Tyler, L.E. (1965) The Psychology of Human Differences. Appleton-Century-Crofts, New York.

[55] Hoyle, R.H. (1993) Interpersonal Attraction in the Absence of Explicit Attitudinal Information. Social Cognition, 11, 309-320. https://doi.org/10.1521/soco.1993.11.3.309

[56] Selfhout, M. and Denissen, J. (2009) In the Eye of the Beholder: Perceived, Actual, and Peer-Rated Similarity in Personality, Communication, and Friendship Intensity during the Acquaintanceship Process. Journal of Personality and Social Psychology, 96, 1152-1165. https://doi.org/10.1037/a0014468

[57] Sumner, W.G. (1906) Folkways. Ginn, Boston.

[58] Cramton, C.D. and Hinds, P.J. (2004) Subgroup Dynamics in Internationally Distributed Teams: Ethnocentrism or Cross-National Learning? Research in Organizational Behavior, 26, 231-263. https://doi.org/10.1016/S0191-3085(04)26006-3

[59] Balabanis, G. and Diamantopoulos, A. (2004) Domestic Country Bias, Country-of-Origin Effects, and Consumer Ethnocentrism: A Multidimensional Unfolding Approach. Journal of Academy of Marketing Science, 32, 80-95. https://doi.org/10.1177/0092070303257644

[60] Le Vine, R.A. and Campbell, D.T. (1972) Ethnocentrism: Theories of Conflict, Ethnic Attitudes, and Group Behaviour. John Wiley, New York.

[61] Turner, J.C. (1985) Social Categorization and the Self-Concept: A Social Cognitive Theory of Group Behavior. In: Lawler, E., Ed., Advances in Group Processes, JAI Press, Greenwich, 77-121.

[62] Tajfel, H. and Turner, J.C. (1986) The Social Identity Theory of Intergroup Behaviour. In: Worchel, S. and Austin, W.G., Eds., Psychology of Intergroup Relations, Nelson, Chicago, 7-24.

[63] Turner, J.C. (1975) Social Comparison and Social Identity: Some Prospects for Intergroup Behavior. European Journal of Social Psychology, 5, 5-34. https://doi.org/10.1002/ejsp.2420050102

[64] Foster, G. (2005) Making Friends: A Non-Experimental Analysis of Social Pair Formation. Human Relations, 58, 1443-1465. https://doi.org/10.1177/0018726705061313

[65] Konrad, A.M., Seidel, M.D.L., Lo, E., Bhardwaj, A. and Qureshi, I. (2017) Variety, Dissimilarity, and Status Centrality in MBA Networks: Is the Minority or the Majority More Likely to Network across Diversity? Academy of Management Learning 
\& Education, 16, 349-372. https://doi.org/10.5465/amle.2015.0256

[66] Lee, S.H.M., Qureshi, I., Konrad, A.M. and Bhardwaj, A. (2014) Proactive Personality Heterophily and the Moderating Role of Proactive Personality on Network Centrality and Psychological Outcomes: A Longitudinal Study. Journal of Business and Psychology, 29, 381-395. https://doi.org/10.1007/s10869-013-9320-y

[67] Armstrong, J.S. and Overton, T. (1977) Estimating Nonresponse Bias in Mail Surveys. Journal of Marketing Research, 14, 396-402. https://doi.org/10.2307/3150783

[68] Phinney, J.S. (1992) The Multigroup Ethnic Identity Measure: A New Scale for Use with Diverse Groups. Journal of Adolescent Research, 7, 156-176. https://doi.org/10.1177/074355489272003

[69] Chemers, M.M., Hu, L. and Garcia, B.F. (2001) Academic Self-Efficacy and First Year College Student Performance and Adjustment. Journal of Educational Psychology, 93, 55-64. https://doi.org/10.1037/0022-0663.93.1.55

[70] Sharma, P. (2010) Measuring Personal Cultural Orientations: Scale Development and Validation. Journal of the Academy of Marketing Science, 38, 787-806. https://doi.org/10.1007/s11747-009-0184-7

[71] Shimp, T.A. and Sharma, S. (1987) Consumer Ethnocentrism: Construction and Validation of the CETSCALE. Journal of Marketing Research, 24, 280-289. https://doi.org/10.1177/002224378702400304

[72] Currarini, S., Jackson, M.O. and Pin, P. (2009) An Economic Model of Friendship: Homophily, Minorities, and Segregation. Econometrica, 77, 1003-1045. https://doi.org/10.3982/ECTA7528

[73] Podsakoff, P.M., MacKenzie, S.B., Lee, J.-Y. and Podsakoff, N.P. (2003) Common Method Biases in Behavioral Research: A Critical Review of the Literature and Recommended Remedies. Journal of Applied Psychology, 88, 879-903. https://doi.org/10.1037/0021-9010.88.5.879

[74] Harman, H.H. (1967) Modern Factor Analysis. University of Chicago, Chicago.

[75] Liang, H., Saraf, N., Hu, Q. and Xue, Y. (2007) Assimilation of Enterprise Systems: The Effect of Institutional Pressures and the Mediating Role of Top Management. MIS Quarterly, 31, 59-87. https://doi.org/10.2307/25148781

[76] Obadia, C. (2013) Competitive Export Pricing: The Influence of the Information Context. Journal of International Marketing, 21, 62-78. https://doi.org/10.1509/jim.12.0164

[77] Steenkamp, J.-B., De Jong, M.G. and Baumgartner, H. (2010) Socially Desirable Response Tendencies in Survey Research. Journal of Marketing Research, 47, 199-214. https://doi.org/10.1509/jmkr.47.2.199

[78] Ringle, C.M., Wende, S. and Will, S. (2005) SmartPLS 2.0 (M3) Beta (Hamburg).

[79] Chin, W.W. (1998) The Partial Least Squares Approach to Structural Equation Modeling. Modern Methods for Business Research, 295, 295-336.

[80] Mitchell, R., Boyle, B., Parker, V., Giles, M., Joyce, P. and Chiang, V. (2014) Transformation through Tension: The Moderating Impact of Negative Affect on Transformational Leadership in Teams. Human Relations, 67, 1095-1121. https://doi.org/10.1177/0018726714521645

[81] Hair, J.F. Jr., Hult, G.T.M., Ringle, C. and Sarstedt, M. (2014) A Primer on Partial Least Squares Structural Equation Modeling (PLS-SEM). Sage, Thousand Oaks.

[82] Kumar, A., Heide, J.B. and Wathne, K.H. (2011) Performance Implications of Mismatched Governance Regimes across External and Internal Relationships. Journal 
of Marketing, 75, 1-17. https://doi.org/10.1509/jmkg.75.2.1

[83] Fornell, C. and Larcker, D.F. (1981) Evaluating Structural Equation Models with Unobservable Variables and Measurement Error. Journal of Marketing Research, 28, 39-50. https://doi.org/10.1177/002224378101800104

[84] Jones, L.M. and Fischer, C.S. (1978) Studying Egocentric Network by Mass Survey. Working Paper at the Institute of Urban and Regional Development, University of California, Berkeley.

[85] Knoke, D. and Yang, S. (2008) Social Network Analysis. Sage Publications, Thousand Oaks.

[86] Falk, R.F. and Miller, N.B. (1992) A Primer for Soft Modeling. University of Akron Press, Akron.

[87] Henseler, J., et al. (2014) Common Beliefs and Reality about PLS: Comments on Rönkkö and Evermann (2013). Organizational Research Methods, 17, 182-209. https://doi.org/10.1177/1094428114526928

[88] Wheeler, V.A. and Ladd, G.W. (1982) Assessment of Children's Self-Efficacy for Social Interactions with Peers. Developmental Psychology, 18, 795-805. https://doi.org/10.1037/0012-1649.18.6.795

[89] Pillai, K.G., Hodgkinson, G.P., Kalyanaram, G. and Nair, S.R. (2017) The Negative Effects of Social Capital in Organizations: A Review and Extension. International Journal of Management Reviews, 19, 97-124. https://doi.org/10.1111/ijmr.12085 


\section{Appendix: Operationalization of the Study Variables}

\begin{tabular}{ll}
\hline Scales & PLS factor \\
& loading \\
\hline
\end{tabular}

\section{Identity salience}

Please indicate how much you agree/disagree with each of the following statements. Seven-point Likert scale ( 1 = "strongly disagree," and 7 = "strongly agree"), adapted from [69].

1) I have a clear sense of my ethnic background and what it means for me.

2) I have a strong sense of belonging to my own ethnic group.

3) I understand pretty well what my ethnic group memberships mean to me, in terms of how to relate to my own group and other groups.

4) I have a lot of pride in my ethnic group and its accomplishments.

5) I participate in cultural practices of my own group, such as special food, music, or customs.

6) I feel a strong attachment towards my ethnic group.

7) I feel good about my cultural or ethnic background.

\section{Academic self-efficacy}

Please indicate how much you agree/disagree with each of the following statements. Seven-point Likert scale ( 1 = "strongly disagree," and 7 = "strongly agree"), adapted from $[70]$.

1) I am good at researching and writing university level papers.

2) I am a very good student.

3) I usually do very well in university and at academic tasks.

4) I typically find my academic work interesting and absorbing.

5) I am very capable of succeeding at the university.

\section{Individualism}

Please indicate how much you agree/disagree with each of the following statements. Seven-point Likert scale ( 1 = "strongly disagree," and 7 = "strongly agree"), based on [71] and [51].

1) I enjoy being unique and different from others in many ways.

2) I often "do my own thing".

3) I am a unique individual.

4) I would rather depend on myself than others.

\section{Ethnocentrism}

Please indicate how much you agree/disagree with each of the following statements. Seven-point Likert scale ( 1 = "strongly disagree," and 7 = "strongly agree"), adapted from [72].

1) It is not right to purchase foreign products because it puts my countrymen out of jobs. 0.77

2) A real patriot should always buy domestically-produced products.

3) We should purchase products manufactured domestically instead of letting other countries get rich off us.

4) My countrymen should not buy foreign products because this hurts indigenous companies and causes unemployment.

\section{Homophily}

Index-based measure that takes into consideration the number of same-nationality ties a student cited in proportion of the number of same nationality ties available taking in consideration the total number of individuals in the group. The measure was adopted from [73]. 